\title{
Performance Study of Solar Power Source for Wireless Systems
}

\author{
Gustaw Mazurek
}

\begin{abstract}
Photovoltaic (PV) technology is an attractive power source for systems with no wired connections to any network. Because of seasonal variations of solar irradiation, designing such a system requires careful analysis in order to provide required level of reliability. In this paper we present results of 16-month measurements of experimental PV system located in Poland. Obtained irradiation values have been verified with reference data from independent sources. The results of this work may be helpful in forecasting the performance of similar PV systems in the same region and allow to make more precise forecasts of power system performance than based only on average monthly irradiation tables.
\end{abstract}

Keywords-photovoltaics, renewable energy, solar irradiation, wireless power systems

\section{INTRODUCTION}

$\mathbf{S}$ OLAR energy seems to be very attractive way of delivering power to several electronic devices located in places with limited or even disabled access to power grid. It can be useful especially in case of low-voltage DC-powered wireless systems, like e.g. distant cellular base stations, weather or traffic monitoring stations, wireless network access points, railway communication, wireless sensor networks, bicycle sharing systems, or even traffic calming radar speed detectors. Application of photovoltaic (PV) power source allows these systems to operate completely stand alone, i.e. without any wired connection with surroundings. Additional advantage of this power source is that it compounds of only electrical components and simple light-weight mechanical constructions with no moving parts, so very low maintenance efforts are required.

As the prices of solar modules have dropped significantly, photovoltaic becomes more and more attractive way of renewable energy production. The amount of electric energy produced in PV installation depends on many factors, like the number and size of PV cells, geographical location of the site, geometry of installation, and so on. However, the most dominant factor is solar irradiation, i.e. the intensity of solar radiation delivered to the $\mathrm{PV}$ surface during a period of time. This parameter strictly depends on climate conditions in the installation site, as well as apparent movement of the sun throughout the day and throughout the year.

A knowledge of the availability of the solar resource at any place is required in all applications of solar energy. For this purpose, various empirical and statistical models have been developed in order to estimate the solar radiation around the world [1]. There are also numerous databases

G. Mazurek is with the Institute of Electronic Systems, Warsaw University of Technology, 15/19 Nowowiejska Str., 00-665 Warsaw, Poland (e-mail g.mazurek@elka.pw.edu.pl). of measurement results collected for almost any place in the world. Most of them is based on remote observations. This method, called Heliosat [2], converts images acquired by meteorological geostationary satellites, such as Meteosat (Europe), GOES (USA) or GMS (Japan), into data and maps of solar radiation received at ground level. A good example of a reliable data source is the HelioClim Server, maintained by the Centre Energétique et Procédés of Ecole des Mines de Paris [3], or NASA Atmospheric Science Data Center [4]. The European Commision has also founded Photovoltaic Geographical Information System (PVGIS) [5] that provides geographical assessment of solar resource and performance of PV technology. This free yet very powerful web service allows to investigate the performance of grid-connected or stand alone PV systems, as well as monthly and daily global irradiation data for any place located in Europe and Africa. It also provides other climatic PV-related databases (e.g. Linke turbidity, ratio of diffuse to global radiation). The forecasts can be based on two alternative databases: Classic PVGIS or Climate-SAF PVGIS.

Measured monthly average values of daily irradiation are the most widely available data and provide a good starting point for calculations. These measurements, however, do not take into account all the factors that have influence to PV energy generation. The amount of generated energy also depends on the tilt angle of the module, operating temperature [6], spectral characteristics, efficiency loss during weak-light operation [7],[8], temporary dirt and snow coverage, and the reflectivity of the surfaces surrounding the installation site.

In [9], a novel stochastic simulation model has been developed that is based on a statistical analysis of the solar radiation data for a given site. It simulates different factors of PV system with backup battery and the performance for the entire year. The model makes use of NASA's Surface meteorology and Solar Energy database [4] for the years 1990-2004 for various cities in Europe with a different climate. However, it does not take into account other previously mentioned factors that have influence to PV energy generation.

In order to consider solar power as the only source of energy for wireless systems and other stand alone applications, the reliability of PV energy source has to be carefully estimated. In this paper we present performance measurements of an experimental PV installation placed in Central Europe (Poland). This installation has being working constantly since 25 th of March, 2012. During this time we have gathered measurements of electrical energy produced in a typical PV module in every day of the year. These results are then statistically analyzed and compared with predictions based on insolation tables obtained from independent sources. 


\section{EXPERIMENTAL PV InSTALlation}

The main part of the experimental system is an economical polycrystalline silicon module (Celline CL005-12P). The module has been fixed on the flat roof of a two-storey building, as shown in Fig. 1. The PV cells in the module are covered by a typical highly transmissive tempered glass without any lens or concentrator. The site is located in a residential area of a small town in Poland $\left(51^{\circ} 03^{\prime} \mathrm{N}, 21^{\circ} 04^{\prime} \mathrm{E}\right), 264$ meters above the mean sea level.

The solar module has been directed to south and there are no obstacles that could obscure the sun on its path across the sky (like trees or buildings) with elevation angles higher than $10^{\circ}$. The tilt of the module is set to optimal year-round angle [10], equal to the latitude ( $\beta=51^{\circ}$, measured from the horizontal). Main parameters of the solar module are summarized in Tab. I. The power has been rated for Standard Test Conditions (STC, irradiance $I_{0}=1 \mathrm{~kW} / \mathrm{m}^{2}$, temperature $25{ }^{\circ} \mathrm{C}$, air mass 1.5 ).

TABLE I

EXPERIMENTAl Solar Module Parameters

\begin{tabular}{|l|c|c|}
\hline Parameter & Symbol & Value \\
\hline Rated power & $P_{\max }$ & $5 \mathrm{~W}$ \\
Rated current & $I_{\operatorname{mpp}}$ & $0.30 \mathrm{~A}$ \\
Rated voltage & $V_{\operatorname{mpp}}$ & $16.5 \mathrm{~V}$ \\
Short-circuit current & $I_{s c}$ & $0.34 \mathrm{~A}$ \\
Open circuit voltage & $V_{o c}$ & $21.0 \mathrm{~V}$ \\
Number of PV cells & & 36 \\
Dimensions & & $350 \times 180 \times 17 \mathrm{~mm}$ \\
\hline
\end{tabular}

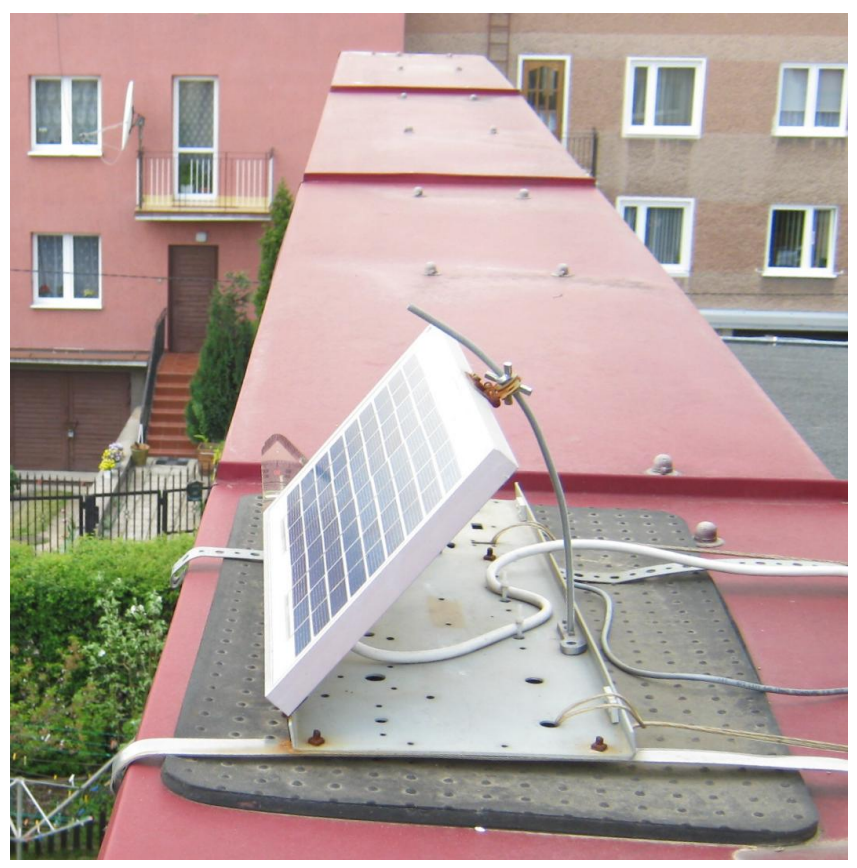

Fig. 1. Experimental solar module installation.

Output terminals of the PV module are connected to a 15 meter cable with other side connected to a dummy resistive load $\left(R_{L}=55 \Omega\right)$ and to input of a data acquisition unit (DAQ). The load resistance $\left(R_{L}\right)$ has been optimized for maximum power point $\left(I_{m p p}, V_{m p p}\right)$ of the module characteristic. The solar module has been inspected and cleaned in every three months, except for winter, when the roof was covered by snow.

\section{A. Data Acquisition System}

In Fig. 2 we can see the block diagram of the system. The voltage $U_{p}$ produced by a photovoltaic module under a resistive load $R_{L}$ is measured with $\pm 40 \mathrm{mV}$ accuracy in a simple telemetry / DAQ device [11]. In a junction box of the PV module there is a temperature sensor T1 which also connected to DAQ input. This allows to measure the operating temperature of the PV module. Additional temperature sensor $\mathrm{T} 2$ is installed in a shadowed location in order to measure the outdoor temperature, regardless of the solar radiation intensity. Temperature measurements, however, are not discussed in this paper. The temperature effects in PV energy production will be subjected to further investigations.

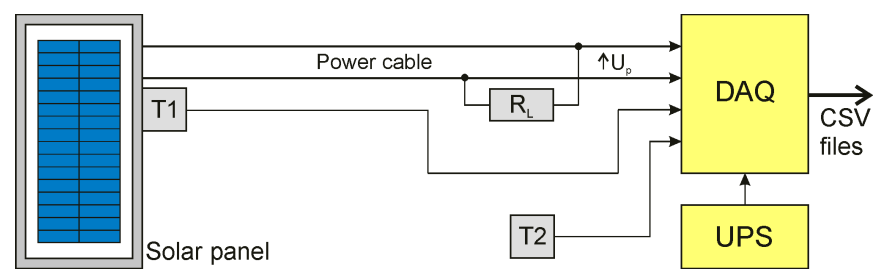

Fig. 2. Block diagram of experimental system.

In every period of $T_{s}=5$ minutes, the module operating voltage $U_{p}$ is sampled and stored in a memory buffer, together with temperature measurements. The measurements taken during the night (after 8:00 pm) and early morning (before 6:00 am) are discarded. This results in $N_{s}=168$ samples $U_{p}(n, i)$ $\left(i=1, \ldots, N_{s}\right)$ of voltage for each $n$-th day in the month.

In Fig. 3, the example measurement results of the solar module voltage $U_{p}$ and temperature $T_{p}$ are depicted. These results were recorded just after the summer solstice, during one of the longest days in the year, with some clouds in the sky. The voltage $U_{p}$ measured at 6 am and at 8 pm yields less than $0.3 \%$ of the solar module rated power. The discarded morning and evening measurements have therefore negligible impact to the measurements of total daily irradiation.

After end of each month, the contents of the memory buffer is downloaded from DAQ and subjected to analysis in a dedicated software. This way we have gathered measurement results of PV system working in a real conditions during more than a year since March 2012.

\section{B. Solar Module and Load Characteristics}

The characteristics of experimental PV module are depicted in Fig. 4. The U-I curves for different solar irradiance levels have been reconstructed with using algorithm published in [12], based on module ratings from Tab. I and general properties of crystalline silicon solar cells [13]. Maximum power point (MPP) for each irradiance level is marked with circle and a red dashed line shows the characteristics of the resistive load. Intersection of this line with a source characteristic (PV module U-I curve) shows the operating point of the module with resistive load for a given solar irradiance level. 


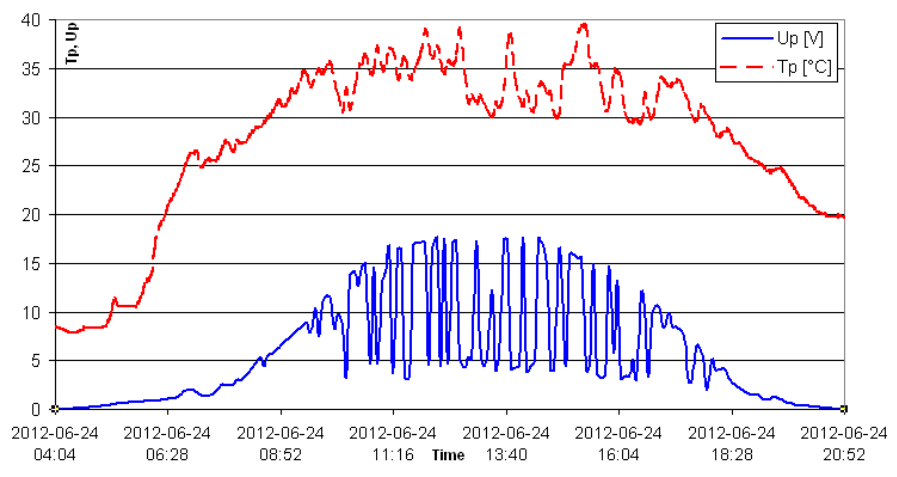

Fig. 3. Example measurements of module voltage and temperature.

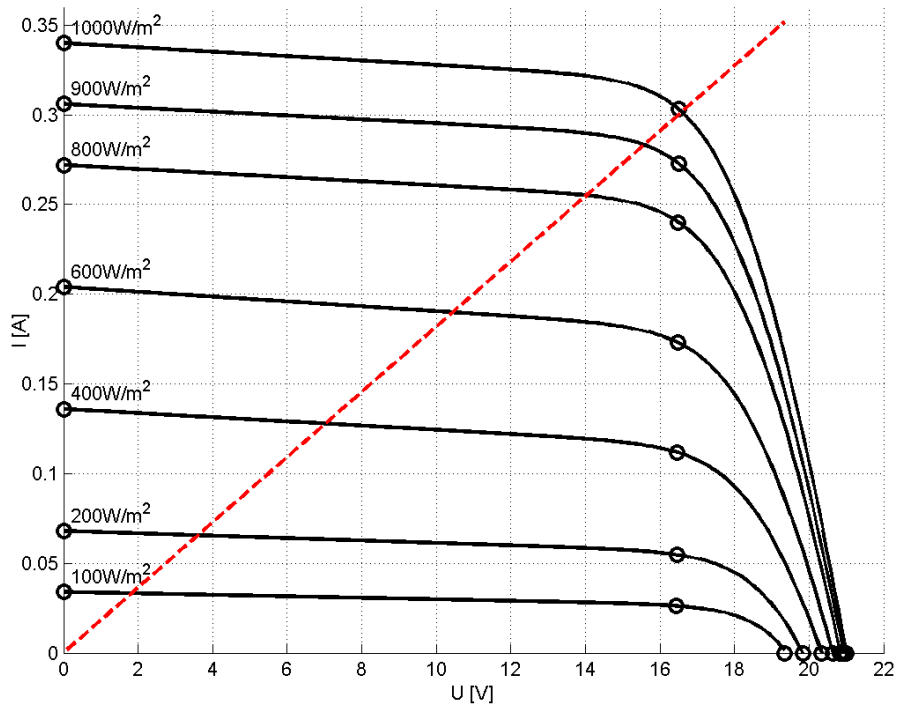

Fig. 4. Voltage - current characteristics of PV module and resistive load.

From Fig. 4 we can confirm that the resistive load is optimal only for the highest irradiance level $\left(1000 \mathrm{~W} / \mathrm{m}^{2}\right)$, because the operating point agrees with MPP. For lower irradiances, however, the intersection point is distant from MPP and the power received by the resistive load is lower than can be produced by the module with an optimal load. Therefore, in order to estimate the power production capabilities of the PV module, load compensation algorithm must be applied to measurements of $U_{p}$ voltages on $R_{L}$ load, already recorded during the last sixteen months.

For different irradiance levels we have numerically evaluated source - load characteristics intersection points. Voltage coordinates of these points, together with corresponding MPP values are marked with crosses in Fig. 5. Then we have numerically evaluated coefficients of an approximation polynomial that fits the experimental $\left(U_{p}, P_{m p p}\right)$ points in a least squares sense:

$P_{m p p}(u)= \begin{cases}2.47 \cdot 10^{-4} u^{3}-2.14 \cdot 10^{-3} u^{2}+ & \\ +0.267 u-0.024 & \text { if } u>0.09, \\ 0 & \text { if } u \leq 0.09 .\end{cases}$

The plot of polynomial (1) is shown with a solid red line in Fig. 5. As a reference there we have also shown a plot of hy- pothetical linear relationship $P_{l i n}(u)$ and a square relationship $P_{s q r}(u)$ between the voltage and power on resistive load $R_{L}$ :

$$
\begin{array}{r}
P_{l i n}(u)=\frac{u P_{\text {max }}}{V_{\text {mpp }}}, \\
P_{s q r}(u)=\frac{u^{2}}{R_{L}} .
\end{array}
$$

From Fig. 5 we can clearly see that the power dissipated in a fixed resistive load $\left(P_{s q r}(u)\right.$, dashed line) is always lower than MPP, in exception for STC irradiation level $\left(1000 \mathrm{~W} / \mathrm{m}^{2}\right)$. The polynomial (1) plot that is situated between the linear and square characteristics allows to estimate MPP for all irradiance levels based on the voltage $U_{p}$ measured on the resistive load.

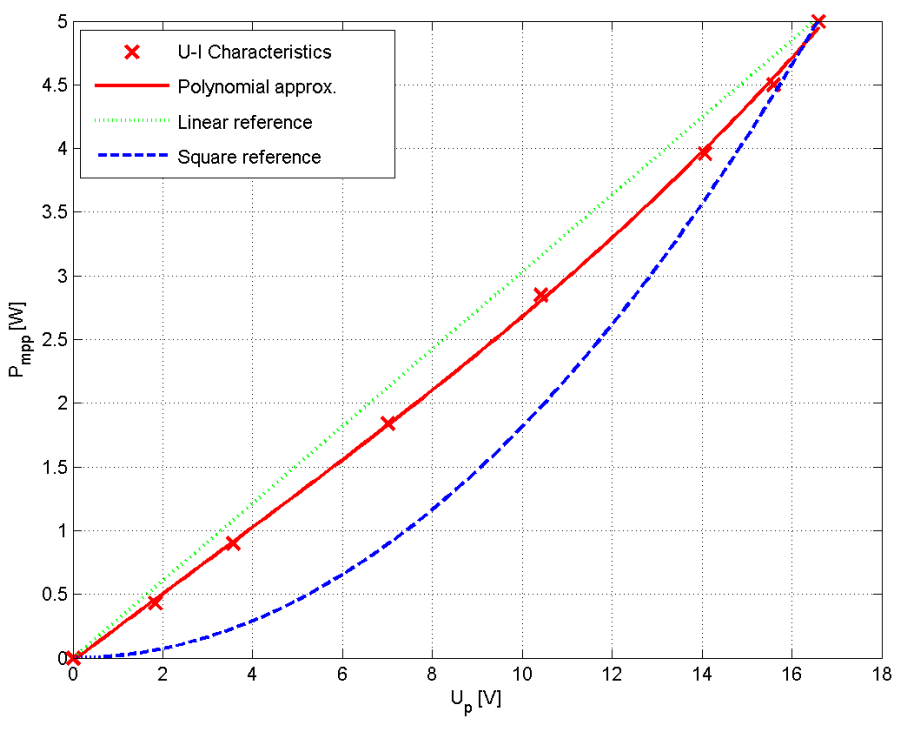

Fig. 5. Estimation of maximum power point based on load voltage.

\section{Power Calculations}

Given the $N_{s}$ sample measurements of solar module operating voltage $U_{p}(n, i)$ for the complete $n$-th day in the month, daily generated energy can be estimated as follows:

$$
E_{d}(n)=\sum_{i=1}^{N_{s}} P_{m p p}\left[U_{p}(n, i)\right] T_{s},
$$

where $P_{m p p}$ is the approximation polynomial (1). We assume that module load is optimal, MPP-tracking (MPPT). Energy produced during a day can be then normalized by the module rated power:

$$
H_{T}(n)=\frac{E_{d}(n)}{P_{\max }} I_{0}, \quad \text { where } I_{0}=1 \mathrm{~kW} / \mathrm{m}^{2} .
$$

Equation (4) estimates a total daily insolation on a tilted plane in $\mathrm{kWh} / \mathrm{m}^{2}$ [13] and it allows to forecast energy generated in PV modules and arrays of different sizes and with the same location, orientation and tilt angle. 


\section{Statistical Analysis of Solar IrRAdiation}

The values of daily solar irradiation $H_{T}(n)$, gathered for each day in the month during the last sixteen months, have been subjected to a basic statistical analysis in Matlab environment. We have aggregated the results from the same months in years 2012 and 2013. After that, we have treated each month results as a separate data vector, in order to track seasonal changes of insolation.

\section{A. Probability Distribution}

We estimate the tail distribution, i.e. complementary cumulative distribution function (ccdf) of daily insolation $H_{T}$ on a tilted plane for each month by counting the number $N_{t}$ of days with insolation (4) exceeding a given threshold $t$ :

$$
F_{c}(t)=N_{t} / N_{d} \approx \mathrm{P}\left[H_{T}>t\right],
$$

where $N_{d}$ is the number of daily measurements recorded for the month. This function is useful in prediction of system availability. It allows to estimate the probability that a daily insolation will exceed a given threshold resulting from power demands of the solar-powered system.

In Fig. 6 we can see ccdf plots for winter months. It is clear that for January and February we could exceed $2 \mathrm{kWh} / \mathrm{m}^{2}$ of daily insolation with the probability around $10 \%$. Since the distribution for December is falling less rapidly, we could exceed the same level with probability of ca. $23 \%$.

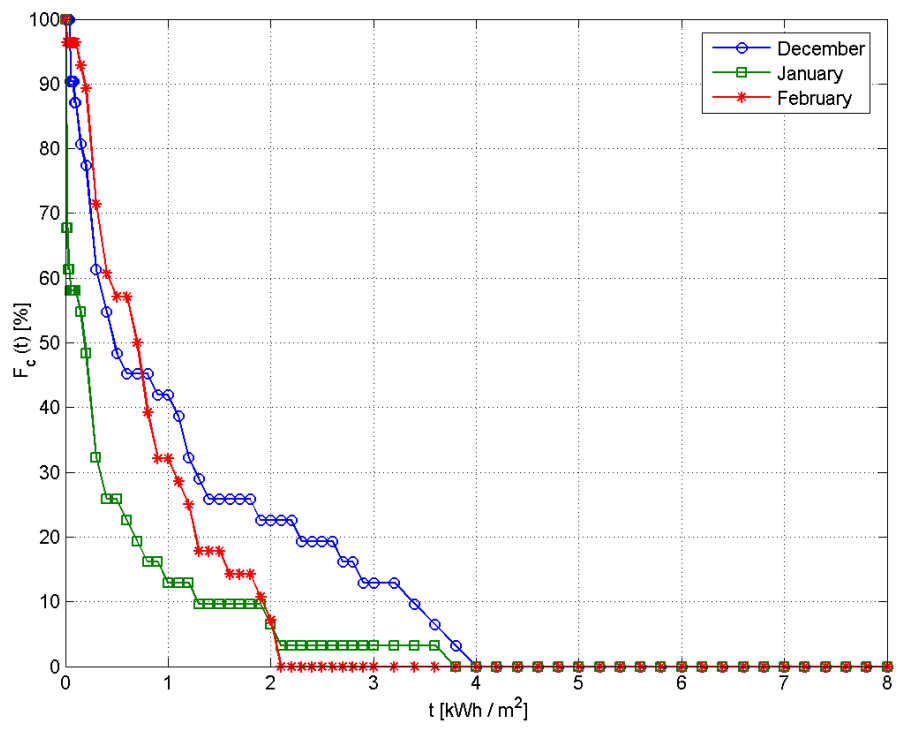

Fig. 6. CCDF of winter insolation.

The tail distribution plots for summer are depicted in Fig. 7. In June and August we could achieve $4.5 \mathrm{kWh} / \mathrm{m}^{2}$ of daily insolation with the probability around $50 \%$. With the same probability we could achieve ca. $5.6 \mathrm{kWh} / \mathrm{m}^{2}$ in July, which is the most sunny month during a year. The system could deliver even more energy during summer if the tilt angle $\beta$ was lower. However, such a tilt angle was selected as a compromise to provide all-year operation.

The spring and autumn ccdf plots, shown in Figs. 8, 9, respectively, are transitional between summer and winter. The ccdf plot for November is falling very rapidly, just like in winter, whereas the distribution for September and October are similar to those in April and March.

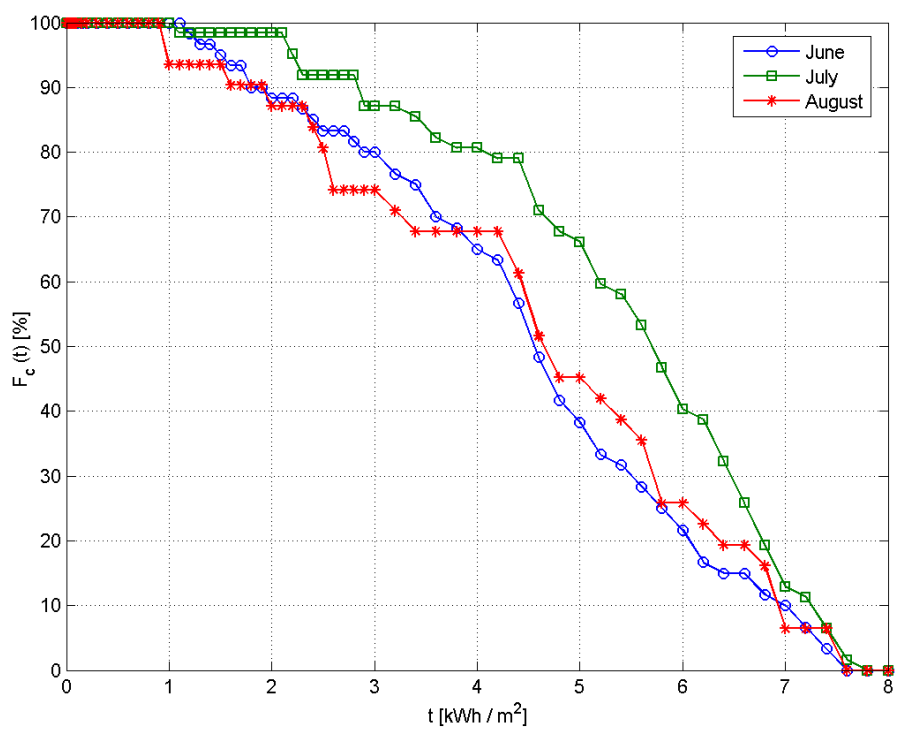

Fig. 7. CCDF of summer insolation.

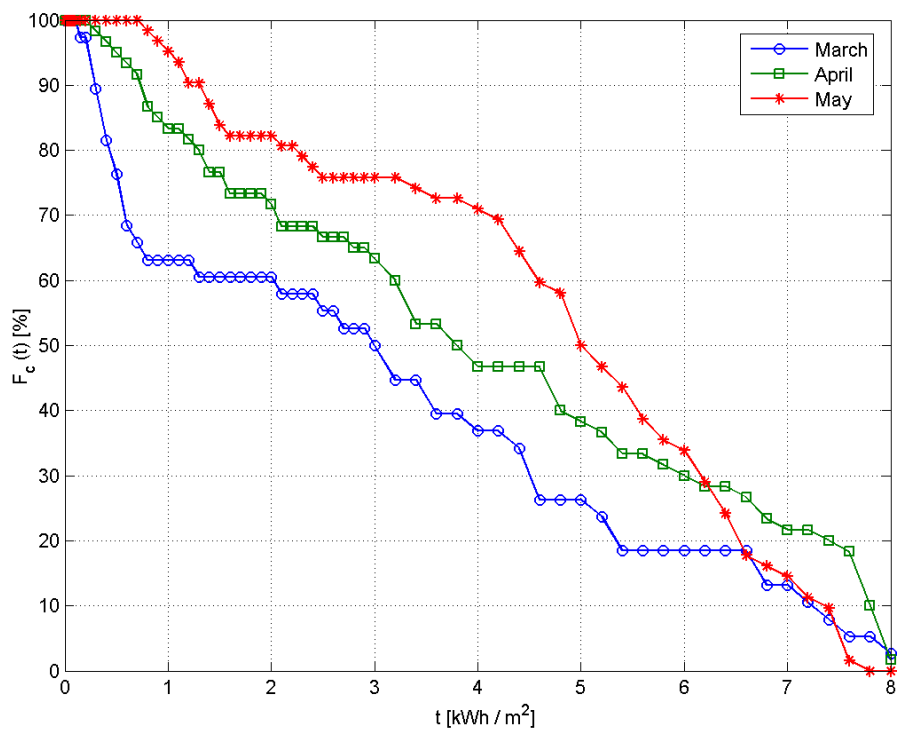

Fig. 8. CCDF of spring insolation.

\section{B. Moments}

For each month we have determined the minimum, maximum, and median value of daily insolation $H_{T}$. We have also evaluated the mean value

$$
\mu=\frac{1}{N_{d}} \sum_{n=1}^{N_{d}} H_{T}(n),
$$

the standard deviation

$$
\sigma=\sqrt{\frac{1}{N_{d}-1} \sum_{n=1}^{N_{d}}\left[H_{T}(n)-\mu\right]^{2}},
$$




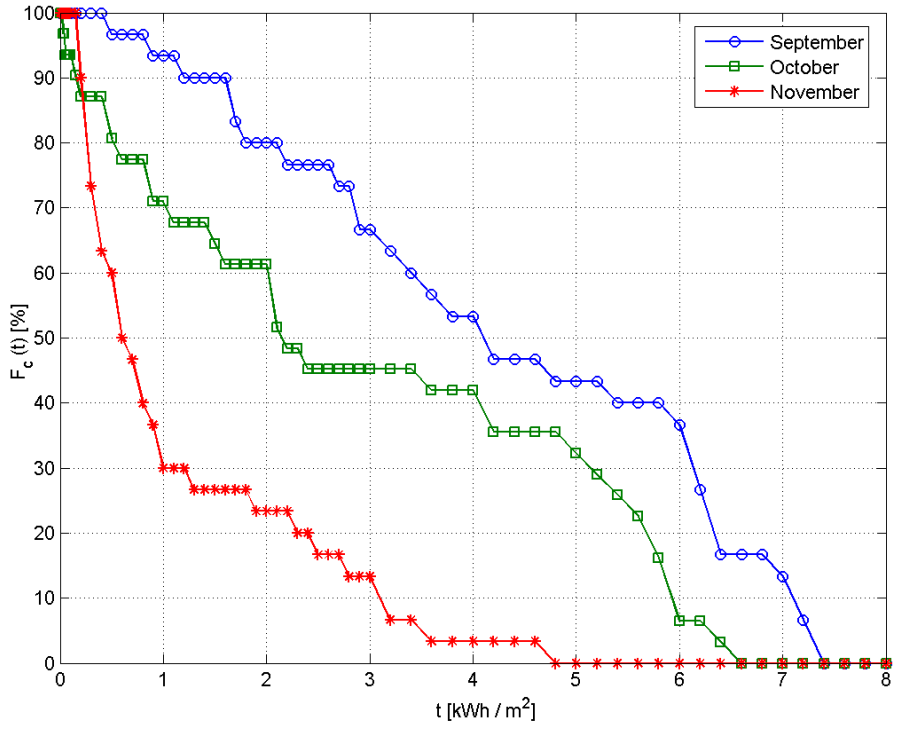

Fig. 9. CCDF of autumn insolation.

and the sample skewness

$$
\gamma=\frac{1}{N_{d} \sigma^{3}} \sum_{n=1}^{N_{d}}\left[H_{T}(n)-\mu\right]^{3} .
$$

The plots of $\mu, \sigma$ for each month are shown in Fig. 10, together with minimal, maximal and median values. The

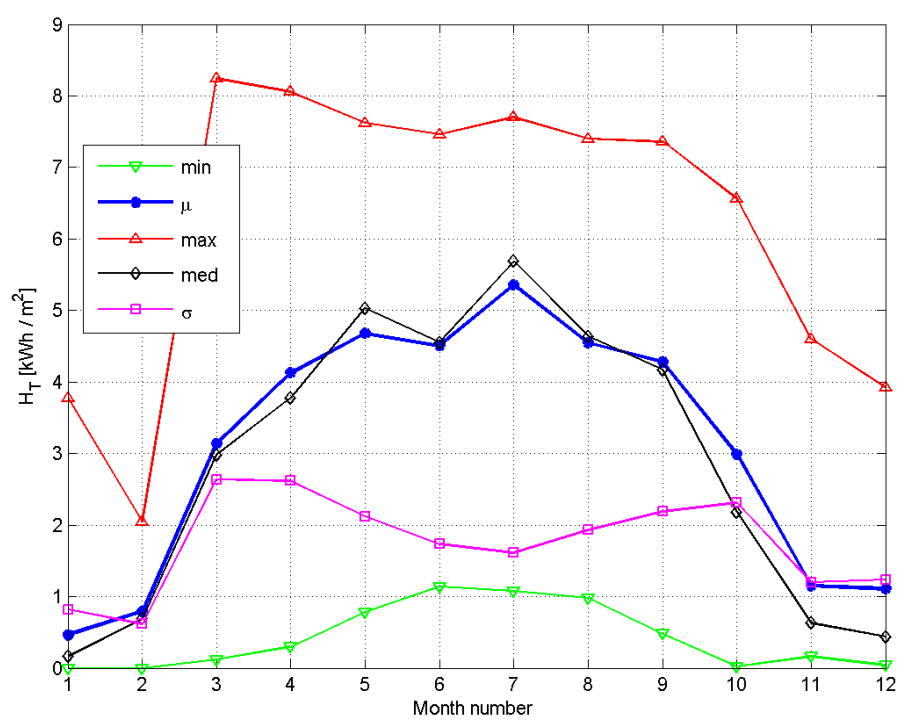

Fig. 10. Sample moments for each month.

results of calculations have been summarized in Tab. II, in which the second column $\left(N_{d}\right)$ shows the number of samples (daily insolation values) recorded during a given month. From March till July we have aggregated samples available from two years of measurement. For the remaining months, only samples from a single year (2012 or 2013) have been available.

In the column with minimum values we can see that in some days in January, February, October and December the experimental PV system produces almost no energy. Estimated
TABLE II

Sample Moments of Daily Insolation $H_{T}$ For all Months of the YEAR

\begin{tabular}{|c|c|c|c|c|c|c|c|}
\hline Month & $N_{d}$ & Min & $\mu$ & Max & Median & $\sigma$ & $\gamma$ \\
\hline 1 & 31 & 0.00 & 0.46 & 3.78 & 0.16 & 0.82 & 2.55 \\
2 & 28 & 0.00 & 0.79 & 2.04 & 0.69 & 0.62 & 0.75 \\
3 & 38 & 0.12 & 3.14 & 8.24 & 2.98 & 2.64 & 0.43 \\
4 & 60 & 0.30 & 4.13 & 8.06 & 3.78 & 2.62 & 0.09 \\
5 & 62 & 0.78 & 4.68 & 7.62 & 5.03 & 2.12 & -0.48 \\
6 & 60 & 1.14 & 4.51 & 7.46 & 4.55 & 1.73 & -0.15 \\
7 & 62 & 1.08 & 5.36 & 7.70 & 5.69 & 1.61 & -0.71 \\
8 & 31 & 0.98 & 4.55 & 7.40 & 4.64 & 1.93 & -0.28 \\
9 & 30 & 0.48 & 4.28 & 7.36 & 4.17 & 2.19 & -0.12 \\
10 & 31 & 0.02 & 2.99 & 6.56 & 2.18 & 2.31 & 0.16 \\
11 & 30 & 0.16 & 1.15 & 4.60 & 0.63 & 1.20 & 1.29 \\
12 & 31 & 0.04 & 1.11 & 3.92 & 0.44 & 1.24 & 1.04 \\
\hline
\end{tabular}

insolation (4) does not exceed $0.1 \mathrm{kWh} / \mathrm{m}^{2}$ in those days, despite the tilt angle $\beta$ of the module favors sunlight absorbtion during low elevation angles of the Sun. The mean value $(\mu)$ of $H_{T}$ ranges from 0.46 in January to 5.36 in July. However, in case of autumn and winter, the mean values are noticeably higher than the median and this could lead to overestimated PV energy forecasts. During these months, median value should rather be considered as a reference. For the rest of the year, the median and mean values are very close to each other and average solar insolation tables can serve as a base for PV energy generation forecasts.

The values of sample skewness show that distribution of $H_{T}$ is relatively symmetric in April, June, September and October $(\gamma \approx 0)$. In other months the distribution is skewed to the left (summer) or to the right (winter). This can explain the discrepancies between the mean and median values.

\section{Comparison With Reference Data}

In Fig. 11 we have compared the evaluated monthly mean ( $\mu$ ) values of $H_{T}$ with average daily solar irradiation for the same geographical place and the same tilt angle obtained from both PVGIS databases [5], and with monthly average insolation collated over a 22 year period for Warsaw, available in Solar Electricity Handbook [10].

The experimental results are very close to the reference data during all the months except January, February, and July. Lower than expected results in winter can be explained by temporary snow coverage of the module surface during some winter days which made it blind to a sunlight. Higher than expected results in July are harder to explain and can result from unusually clear sky that exceed the long-term average. The reference results from PVGIS-SAF database seem to be overestimated in comparison to other sources and the measured insolation levels. This database should be used with special care during design of any PV system.

The differences between the experimental results and reference data may be caused by the following reasons:

- heat generated by sunlight on silicon cells causes drop of efficiency and rated power of PV module [6],

- weather conditions during the last year could vary from the long-term average because of climate changes. 


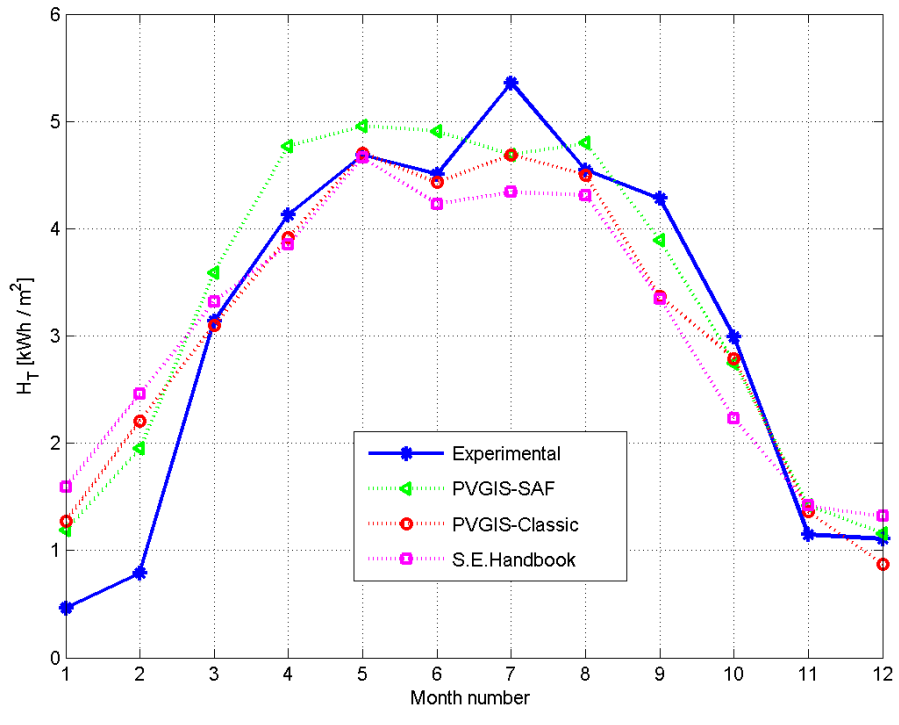

Fig. 11. Measured mean solar irradiation compared with reference data.

\section{Example ApPlications}

In the following calculations we assume that the powered system employs MPPT load that adopts to the changes of PV source characteristics. The parameters from Tab. II can be used to estimate the total energy generated during each month by PV system located in the same climate area and based on the same technology. Such an estimation can be essential for the needs of economical forecasts and can be easily achieved for a selected month by multiplying the corresponding $\mu$ value by the number of days $N_{m}$ in the month and the rated power of PV module or array, defined for STC:

$$
E_{m} \approx \mu N_{m} P_{\max } / I_{0}
$$

With ccdf (tail distribution) plots depicted in Figs. 6, 7, 8, 9 we can estimate the availability of the solar-powered system. We define the availability as the probability that the PV module or array will provide required amount of energy during a day. Given a daily energy consumption $E_{d}$ of a system and the rated power of PV module, we can determine the solar irradiation required each day:

$$
H_{r}=\frac{E_{d}}{P_{\max }} I_{0}
$$

The resulting $H_{r}$ can be used as a threshold in tail distribution plots. For example, a $12 \mathrm{~V}$ DC stand alone system with $35 \mathrm{~mA}$ average current draw (e.g. low-power telemetry or a wireless sensor network node) needs $E_{d}=10 \mathrm{Wh}$. If a small PV module $\left(P_{\max }=5 \mathrm{~W}\right)$ is used, more than $2 \mathrm{kWh} / \mathrm{m}^{2}$ of daily irradiation is required. From Fig. 7 we can see that it could be easily achieved in summer - with probability greater than $90 \%$. In autumn that probability falls to approx. $80 \%$ in September, $60 \%$ in October, and $23 \%$ in November (see Fig. 9). In January and February we have less than $10 \%$ probability of success. In this case the PV module and a backup battery have to be properly expanded, or the power consumption has to be reduced in order to guarantee reliable operation during autumn and winter.

\section{CONCLUSION}

The mean values of solar irradiation can be easily found in different publications. However, they do not give the detailed information on a PV system behavior, because the probability distribution of daily insolation is different in each month. Especially in winter, when the mean values exceed the median, using only mean values could lead to overestimation of power system performance.

In the paper, the performance of an experimental PV power system in all months in the year has been evaluated. During most of the winter days the solar module produced almost no energy, and only a few days gave some improvement. These days, however, are too sparse to provide uninterrupted power for a stand alone system, powered by the photovoltaic module supported by a backup battery.

During other seasons, the results of energy measurements from our experimental system are in agreement with predictions based on tables with monthly averaged global irradiation.

Results of this work should be representative for PV installations in Central Europe employing similar technology. The presented measurements take into account all the factors influencing the system efficiency, e.g. variations of PV cell's temperatures, temporary dirt and snow coverage on the surface, nonlinear response to solar radiation intensity, and the influence of a tilt angle. Based on these results, it is possible to make more precise forecasts of system availability than using only tables with average daily solar irradiation.

\section{REFERENCES}

[1] V. Badescu, Modeling Solar Radiation at the Earth's Surface: Recent Advances. Berlin Heidelberg: Springer-Verlag, 2008.

[2] D. Cano et al., "A method for the determination of the global solar radiation from meteorological satellite data," Solar Energy, vol. 37, no. 1, pp. 31-39, 1986.

[3] Ecole des Mines de Paris, "HelioClim solar radiation," http://www.helioclim.org/, 2013.

[4] NASA, "Surface meteorology and solar energy (SSE) data and information," https://eosweb.larc.nasa.gov/, 2013.

[5] European Commission, Joint Research Centre, "Photovoltaic geographical information system - interactive maps," http://re.jrc.ec.europa.eu/pvgis/apps4/pvest.php, 2013.

[6] A. Goetzberger and V. U. Hoffmann, Photovoltaic Solar Energy Generation. Berlin Heidelberg: Springer-Verlag, 2005.

[7] M. R. Patel, Wind and Solar Power Systems. CRC Press, 1999.

[8] P. Grunow, S. Lust, D. Sauter, C. Beneking, and B. Litzenburger, "Weak light performance and annual yields of PV modules and systems as a result of the basic parameter set of industrial solar cells," in Proc. 19th European Photovoltaic Solar Energy Conference, Paris, France, Jun. 2004, pp. 2190-2193.

[9] E. Kaplani and S. Kaplanis, "A stochastic simulation model for reliable PV system sizing providing for solar radiation fluctuations," Applied Energy, vol. 97, pp. 970-981, 2012.

[10] M. Boxwell, Solar Electricity Handbook, On-line Solar Irradiance Tables. http://www.solarelectricityhandbook.com/solar-irradiance.html, 2013.

[11] PROGSTAR, "SMS-4 Module," http://www.progstar.com.pl/sms4/, 2013.

[12] M. G. Villalva, J. R. Gazoli, and E. R. Filho, "Comprehensive approach to modeling and simulation of photovoltaic arrays," IEEE Transactions on Power Electronics, vol. 24, no. 5, pp. 1198-1208, 2009.

[13] J. A. Duffie and W. Beckman, Solar Engineering of Thermal Processes. New York: Wiley-Interscience, 1980. 